\title{
Enabling interdisciplinary research
}

\author{
From inception to publication, interdisciplinary and transdisciplinary research faces distinct challenges. We are \\ committed to enabling such research through a fair and principled peer review process.
}

$N$ ature Human Behaviour is not your typical journal. Our scope is thematic rather than disciplinary, welcoming research from any - literally any discipline that has something significant to say about human behaviour that will interest others working in this space. When we launched at the beginning of the year, we made a point to encourage the submission of interdisciplinary and transdisciplinary research - we are not only a home for different disciplines, but also want to encourage interaction among them that will broaden the scope of enquiry and generate knowledge that transcends disciplinary boundaries.

The response has been overwhelmingly positive and we frequently hear from researchers who work at the intersection of different disciplines how important it is for them to have outlets where interdisciplinary and transdisciplinary research is particularly welcomed. These researchers explain the difficulties they occasionally encounter in publishing their research and the challenges that the peer review process presents for them: their manuscripts are evaluated by reviewers from different disciplinary backgrounds, whose feedback inevitably bears the hallmark of their discipline of origin. As a result, in totality, reviewer feedback can be rich, but contradictory, so that addressing one reviewer's feedback is frequently in conflict with satisfying the concerns of another reviewer.

The peer review of interdisciplinary and transdisciplinary research is a challenge for editors, too. At Nature Human Behaviour, for every manuscript we receive, we seek reviewers that will cover all areas of expertise relevant for its evaluation, both in terms of theory and in terms of methods. It is not untypical for our manuscripts to have reviewers from two or three different disciplines - manuscripts that are evaluated by an economist, a psychologist and a geographer; an epidemiologist, an economist and a neuroscientist; archaeologists and neuroimagers; political scientists and sociologists; and numerous other imaginative combinations dictated by the work at hand. We are amazed by and grateful for the thoughtfulness of our reviewers and their willingness to engage with manuscripts that are frequently beyond the realm of work that typically lands on their desks for peer review. But inevitably, reviewer feedback is more often than not conflicting in fundamental ways. And, although conflicting reviewer feedback is frequent even for manuscripts that belong to a single discipline, the conflict for interdisciplinary or transdisciplinary manuscripts can be such that the manuscript would typically be rejected as invalid if it were submitted to a respected disciplinary journal.

When making decisions, our aim is not to please the reviewers or the authors, but to be fair and respectful to both, and reach decisions that benefit science and its evolution. When it comes to theory, we will always ask authors to take into account related work carried out in other disciplines on the same question - disciplinary silos are harmful for science and impede progress; one discipline cannot ignore what another has spent decades working on. However, we will not reject manuscripts that pose questions that are considered answered in other disciplines if these manuscripts offer empirical data of unprecedented scale or rigour, or use a novel, imaginative approach to answering the question that enriches understanding, even if the core answer to the question remains the same. When it comes to methods, we will hold authors to the methodological standards of the discipline from which the methods were drawn. For instance, the methods of a psychological experiment will be held against the standards of experimental psychology, not experimental economics, and vice versa, even if both disciplines are theoretically relevant to the question the authors are addressing. Frequently, however, methods drawn from one discipline need to be adapted to the needs of another - in those cases, we will ask the authors for robust justifications of their methodological choices, but will not insist on holding them to the methodological standards of the originating discipline. In all cases, we will explain the rationale of our decisions to authors and reviewers, and will encourage them to contact us if they would like to discuss the decision further. If as a reviewer we overruled some aspect of your comments, rest assured that your comments were not ignored - they were carefully considered and are important: ultimately, engagement with other disciplines through the peer review process is a key way to positively influence the development of theory and methods in those disciplines.

Disciplines have a lot to learn from each other and interdisciplinary research, with all its challenges, is invaluable. Our aim is to enable interaction and provide a forum for exchange and ultimately new insight and research directions. As but one example, take a look at this issue's Perspective by Michèle Lamont and colleagues (article no. 0242). Psychology and sociology paradigmatically occupy opposite ends of the individual-society continuum of scientific enquiry. However, Lamont et al. argue, psychology stands to gain from incorporating into the study of individual cognition insights from supra-individual cultural schemas originating in sociological research.

Published online: 7 December 2017 https://doi.org/10.1038/s41562-017-0272-5 